\title{
CONTINUOUS MEDIUM PERFUSION LEADS TO LONG-TERM CELL VIABILITY AND OXYGEN PRODUCTION IN HIGH-DENSITY PHOTOBIOREACTORS
}

\author{
Choul-Gyun Lee and Bernhard O. Palsson ${ }^{1, *}$ \\ Department of Chemical Engineering, University of Michigan, Ann Arbor, MI 48109, USA. \\ ${ }^{1}$ Current address: Department of Bioengineering, University of California - San Diego, \\ La Jolla, CA 92093, USA.
}

\begin{abstract}
SUMMARY
A light-emitting diode-based photobioreactor (LED-based PBR) operated in a continuous perfusion mode with a perfusion rate of 3 to 6 reactor volumes a day supports high-density algal cultures, of cell concentrations up to $4 \cdot 10^{9}$ cells/mL, or $25 \mathrm{~g} / \mathrm{L}$. The oxygen production rate at its peak was 13 to $15 \mathrm{mmol} /(\mathrm{L} \cdot \mathrm{h})$. Continuous medium perfusion allowed for longterm stable oxygen production, while oxygen production in batch mode ceased when stationary phase was reached.
\end{abstract}

\section{INTRODUCTION}

The history of the commercial use of algal cultures spans about 50 years with applications to waste-water treatment, production of biomass, and production of specialty chemicals (e.g. Benemann et. al., 1987; Borowitzka, 1992; Glombitza and Koch, 1989; Hoppe et. al., 1979). Interest has developed in using algae to fix carbon dioxide to produce oxygen and biomass for life-support in space (Gafford and Richardson, 1960; Hannan and Patouillet, 1963), and for reducing $\mathrm{CO}_{2}$ emissions from power plants (Takano et. al., 1992). Unlike the rapid and significant advances in the biotechnological use of bacteria, yeast, and mammalian cells, algal biotechnology and the development of photoautotrophic cultures has progressed relatively slowly in spite of their recognized utility. A constraining factor is the lack of availability of efficient large-scale cultivation techniques and the underdeveloped stage of photobioreactor (PBR) technology.

Large-scale open algal cultures, such as lined and unlined ponds, typically operate at low cell densities (0.01 to $0.06 \% \mathrm{w} / \mathrm{v}$; Avron, 1989), resulting in expensive harvesting procedures and unfavorable economics, in addition to difficulties with species control (Benemann et. al., 1980; Richmond, 1986). High-density photoautotrophic algal cultures have been established using enclosed forms of PBRs. Many of the PBRs described are able to support cell densities up to 5 to $6 \mathrm{~g}$ dry cell/L. A few PBRs are more successful through the construction of special lighting systems (10-17 g/L) (Lee and Palsson, 1994).

The efficient design of bioreactor systems relies on the important principle of balancing physical rate and biological processes that take place in PBRs. The physical rate processes of concern are light delivery, gas mass transfer, and fluid flow and mixing. The biological rate processes of concern are metabolism, photosynthesis, growth and the effects of secondary metabolite build up. We have previously described the performance of a high-density LEDbased PBR (Lee and Palsson 1994; 1995). Here we outline the rates at which nutrients have to be supplied and the waste products removed in order to maintain a viable high density culture in stationary phase over extended periods of time.

\section{MATERIALS AND METHODS}

Strain

Chlorella kessleri (UTEX 398) obtained from The Culture Collection of Algae at UTEX (Austin, TX) were cultured in N-8 medium (Vonshak, 1986). The seed culture was prepared 
by $250 \mathrm{~mL}$ flasks with $100 \mathrm{~mL}$ working volume in an illuminated shake incubator (Model G27, New Brunswick Scientific Co. Inc., Edison, NJ). Inoculum density to the PBRs was about $1.10^{6} \mathrm{cell} / \mathrm{mL}$.

\section{Culture Conditions}

On-line replenishment of medium was performed by perfusion using hollow fiber cartridges (model BR170, UniSyn Technologies, San Diego, CA). Perfusion rates used were 0.15 $\mathrm{mL} / \mathrm{min}$ and $0.30 \mathrm{~mL} / \mathrm{min}$ ( 3 and 6 times the working volume per day, respectively). Two other PBRs were operated parallel to determine the performance increase obtained by continuous perfusion; a PBR with no medium exchange (batch mode) and a PBR with an offline medium exchange (where cells were centrifuged, resuspended in fresh medium, and returned to the PBR) after the cell concentration reached $4 \cdot 10^{7}$ cell $/ \mathrm{mL}$. A peristaltic pump recirculated the culture medium at a rate of $100 \mathrm{~mL} / \mathrm{min}$ to keep the cells in suspension.

Pre-mixed gas with the composition of $10 \% \mathrm{CO}_{2}$ and balanced with $\mathrm{N}_{2}$ was introduced through the gas analyzer and refreshed whenever either the $\mathrm{O}_{2}$ or $\mathrm{CO}_{2}$ concentration had changed more than $1 \%$ from the pre-mixed concentration. A gas recycle rate of $100 \mathrm{~mL} / \mathrm{min}$ through the internal sparger was found to be sufficient $\left(250 \mathrm{mmol} \mathrm{O}_{2} /(\mathrm{L} \cdot \mathrm{h})\right.$ ) to achieve the required gas transfer $\left(100 \mathrm{mmol} \mathrm{O}_{2} /(\mathrm{L} \cdot \mathrm{h})\right)$. Further, sparging helped to mix the culture.

\section{Photobioreactor}

The same PBR system, described earlier (Lee and Palsson, 1994), was used after minor modification to perform continuous perfusion (Fig. 1). The volume of the illumination chamber was $52 \mathrm{~mL}$ (culture depth of $1.00 \mathrm{~cm}$ ) but the total working volume of the PBR system was $70 \mathrm{~mL}$. The total illumination area of each PBR was about $100 \mathrm{~cm}^{2}$. Each illumination chamber had two LED units, one on each side, that consisted of 90 LEDs each. Direct internal illumination by $680 \mathrm{~nm}$ LEDs could deliver as much as $50 \mathrm{~mW} / \mathrm{cm}^{2}$ into the culture medium.

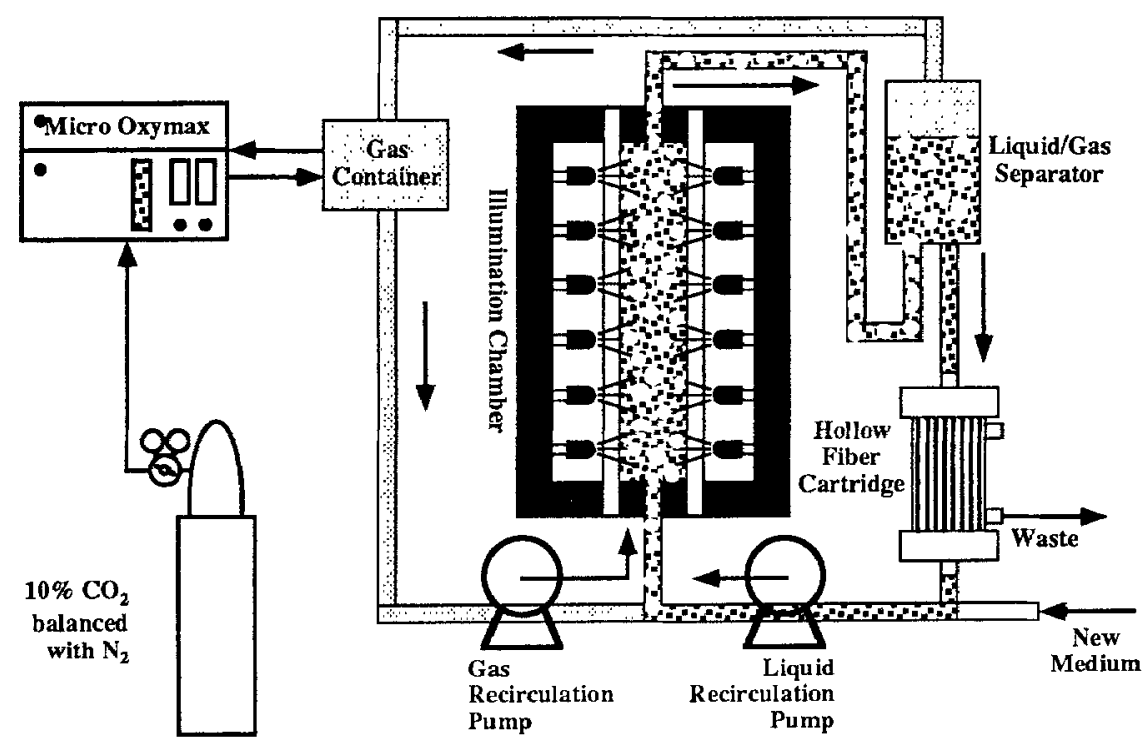

Figure 1. Schematic diagram of the LED-based perfusion PBR. Two peristaltic pumps were used for gas and liquid recirculation at a rate of $100 \mathrm{~mL} / \mathrm{min}$ each. On-line perfusion as gas phase refreshment was performed as described in the text. 


\section{Measurements Performed}

A gas analyzer with high sensitivity was used to measure the oxygen production rate (OPR). A Micro-Oxymax gas analyzer (Columbus Instruments, Columbus, $\mathrm{OH}$ ) was connected to the PBR system through a $500 \mathrm{~mL}$ gas container and the entire gas phase was hermetically sealed to obtain the desired sensitivity (Fig. 1). The gas was recirculated continuously by a separate peristaltic pump and the gas composition in the head space of each PBR was measured at $1 \mathrm{~h}$ intervals using a multiplexer. A longer interval made the gas concentration difference larger between readings, which enabled the detection of small changes in gas phase composition. However, obtaining high sensitivity by this method inevitably introduced some fluctuation in the measurement of the gas phase composition since any changes in pressure or volume (such as sampling and perfusion) affected the OPR calculation.

The cell concentration was determined by Coulter Counter model ZM with a Channelizer model C256 (both from Coulter Electronics, Inc., Hialeah, FL) after proper dilution with isotonic diluent (Fisher Scientific, Pittsburgh, PA). Since the average cell size was highly variable (about $100 \mu \mathrm{m}^{3} /$ cell while the cells are actively growing and about $30 \mu \mathrm{m}^{3} / \mathrm{cell}$ at stationary phase), the specific volumetric growth rate (based on total cell volume) was used to calculate the doubling time. The chlorophyll content of the cells was quantified by using a spectrophotometer (UV-160, Shimadzu, Japan) after diluting to proper concentrations following methanol extraction (Hipkins and Baker, 1986).

\section{RESULTS AND DISCUSSION}

C. kessleri, inoculated at $1.10^{6}$ cells $/ \mathrm{mL}$, did not grow after a cell concentration of $3.10^{8}$. cells $/ \mathrm{mL}$ (about $1 \% \mathrm{v} / \mathrm{v}$ ) was reached when cultivated in batch mode (Fig. 2, denoted by $O$ in all Figs.). When medium components were supplied either by continuous perfusion or by off-line exchange, the same PBR reached a final algal biomass concentration that was an order of magnitude higher than the maximum concentration obtained in batch mode $(\square, \Delta$, and $\vartheta$, respectively, in Fig. 2; same symbols used in all Figs.). The final cell concentrations in a PBR with an off-line medium exchange rate of 1 volume fresh medium per volume reactor per day (1 VVD) was over $7.7 \% \mathrm{v} / \mathrm{v}\left(2.2 .10^{\circ} \mathrm{cells} / \mathrm{mL}\right)$ at $490 \mathrm{~h}$ (Fig. 2) while the PBR with a perfusion rate of 3 VVD supported cell densities up to $8.2 \%$ or $2.9 .10^{9}$ cells $/ \mathrm{mL}$ at the end of the run (Fig. 2). The highest final cell concentration was achieved in the PBR with the highest medium perfusion rate $(6 \mathrm{VVD})$. At 20 days after the inoculation, more than $9.4 \% \mathrm{v} / \mathrm{v}$ of total biomass or $4.10^{9}$ cells/mL was recorded in the PBR system with 6 VVD perfusion (Fig. 2). From this observation, it was apparent that certain forms of medium supply and waste removal were important for $C$. kessleri to overcome the limited cell density obtained in batch mode.

All the cultures in the PBRs with in situ medium supply reached the cell concentration of $1.10^{9}$ cells $/ \mathrm{mL}$ (about $3 \% \mathrm{v} / \mathrm{v}$ ) in about 5 days. When plotted in linear scale (replot of Fig. 2, data not shown), each set of cell concentration data points between $100 \mathrm{~h}$ and $450 \mathrm{~h}$ falls on a straight line. This linear growth phase began to level off after the culture reached $8 \% \mathrm{v} / \mathrm{N}$, regardless of medium supply rate. The cultures were therefore constrained by a limitation other than nutrient availability or waste accumulation at this point.

The timing of the onset of continuous perfusion was found to be important. Starting perfusion before reaching a certain minimum cell concentration was found to be detrimental. The growth rates in the perfused reactors were slow ( $\square$ and $O$ in Fig. 2; fastest doubling time of $14.2 \mathrm{~h}$, or growth rate of $0.049 / \mathrm{h}$ ) compared to the growth rates of the other two PBRs initially operated in batch mode $(O$ and $\Delta$ in Fig. 2; doubling time as low as $8.7 \mathrm{~h}$, or growth rate of $0.080 / \mathrm{h}$ ). The perfusion of the two PBRs with perfusion had to stop for a day (between $50 \mathrm{~h}$ and $74 \mathrm{~h}$ ) in order to expand $C$. kessleri logarithmically. The average doubling time to reach $1 \% \mathrm{v} / \mathrm{v}$ (or about $3.10^{8} \mathrm{cells} / \mathrm{mL}$ at average cell volume of $30 \mu \mathrm{m}^{3} / \mathrm{cell}$ ) was about $15 \mathrm{~h}$ in batch mode and about $20-24 \mathrm{~h}$ for the perfusion mode. When perfusion started after the cell concentration reached $5.10^{7}$ cells $/ \mathrm{mL}$, no growth inhibition was observed 
(data not shown). These observations may be consistent with the secretion of an autocrine growth stimulating factor.

Despite the similar growth patterns in all in situ medium-supplied PBRs, there was a significant difference in the quality of the cultures. Chlorophyll content per cell revealed that the manual medium exchange rate of 1 VVD could not maintain a healthy cell population (Fig. 3). Average chlorophyll content in the PBR with 1 VVD was about half of the two continuously perfused PBRs. Medium exchange with concentrated medium (3X) at $443 \mathrm{~h}$ to this 1 VVD PBR doubled the per cell chlorophyll content temporarily (from $0.25 \mathrm{fmol} / \mathrm{cell}$ to $0.45 \mathrm{fmol} / \mathrm{cel1}$ ). This observation further suggested that some medium components were depleted after the culture reached $1.10^{9}$ cells $/ \mathrm{mL}$. Per cell chlorophyll content in batch mode dropped significantly immediately after the cell concentration reached the plateau at about $100 \mathrm{~h}$, which suggested that the culture was not viable. The average cell volume during the logarithmic growth was 3-4 times Iarger than during stationary phase (data not shown). Therefore the per cell chlorophyll content varied between the two growth phases but chlorophyll content per unit biomass was constant throughout the culture $(0.5 \mathrm{fmol} / 30$ $\mu \mathrm{m}^{3} /$ cell).

The results obtained from the OPR measurement were consistent with these findings. The batch mode PBR stopped producing oxygen after the culture reached $1.10^{8}$ cells $/ \mathrm{mL}$ (thick dotted line in Fig. 4). No chlorophyll content, no oxygen production, and no oxygen consumption suggested that the algae in the batch mode PBR were not viable after $100 \mathrm{~h}$. On the other hand, OPRs from the other three PBRs were stable for a long period. The peak OPR of the PBR with a 6 VVD perfusion rate (thick solid line) was over $15 \mathrm{mmol} /(\mathrm{L} \cdot \mathrm{h}$ ). Oxygen production of the PBR with 3 VVD perfusion (thin dotted line) was between 5 and 8 $\mathrm{mmol} /(\mathrm{L} \cdot \mathrm{h})$ for $400 \mathrm{~h}$ and that of the PBR with $6 \mathrm{VVD}$ was between 6 to $10 \mathrm{mmol} /(\mathrm{L} \cdot \mathrm{h})$ for $300 \mathrm{~h}$. Although the frequent draining and refilling of the culture (1 VVD medium exchange by centrifugation and resuspension) caused a large fluctuation in the OPR reading (thin solid line), a comparable OPR reading was obtained. These results show that an optimized PBR can produce oxygen stable over extended periods of time.

The capacity of $\mathrm{N}-8$ medium for $C$. kessleri culture was about $1 \cdot 10^{8}$ cells $/ \mathrm{mL}$. This concentration is confirmed by the stoichiometric calculations based on the chemical composition of $C$. kessleri and the amount of each component of N-8 medium (Mandalam, 1994). However, previous results on the effects of osmolarity (Mandalam, 1994) and the possible accumulation of potentially harmful cell wastes (Mandalam, 1994; Pratt, 1944; Pratt et. al., 1944) give a significant advantage to algal cultures with perfusion or on-line ultrafiltration over the batch mode cultures with highly concentrated medium.

Plant hormones or growth substances, such as abscisic acid, auxin, cytokinins, and gibberellins, have been reported to affect the growth of macroalgae (Bradley, 1991; Evans, 1991). However, the in vivo concentrations of these growth substances were rarely measured (Evans 1991) and only a few reports used axenic algal culture (Bradley 1991). The possible presence of autocrine growth regulator(s) in $C$. kessleri observed here was particularly interesting since few studies have reported on growth promoting substances in microalgae. It has been reported that the level of free cytokinins in Chlorella was closely associated with the regulatory effects of red light, phytohormones and dichlorophenylurea derivatives (Kreslavsky et. al., 1988). The observation made in this study suggested the presence of autocrine growth regulator(s) in C. kessleri since starting perfusion before the culture reached a certain critical concentration found to be detrimental to cell growth.

Chlorophylls, especially chlorophyll $a$, can be found in every photosynthetic plant cell (Hoover, 1984). They participate in the first step of photosynthesis, photon absorption. Thus, photosynthetic cells cannot grow photoautotrophically without chlorophylls. The data shown here also indicates that the higher the per cell chlorophyll content, the healthier the cell. Thus, per cell chlorophyll content can possibly be used as an indicator of the cell viability, since no other reliable viability measurement is available for $C$. kessleri (Geider and Osborne, 1992). 

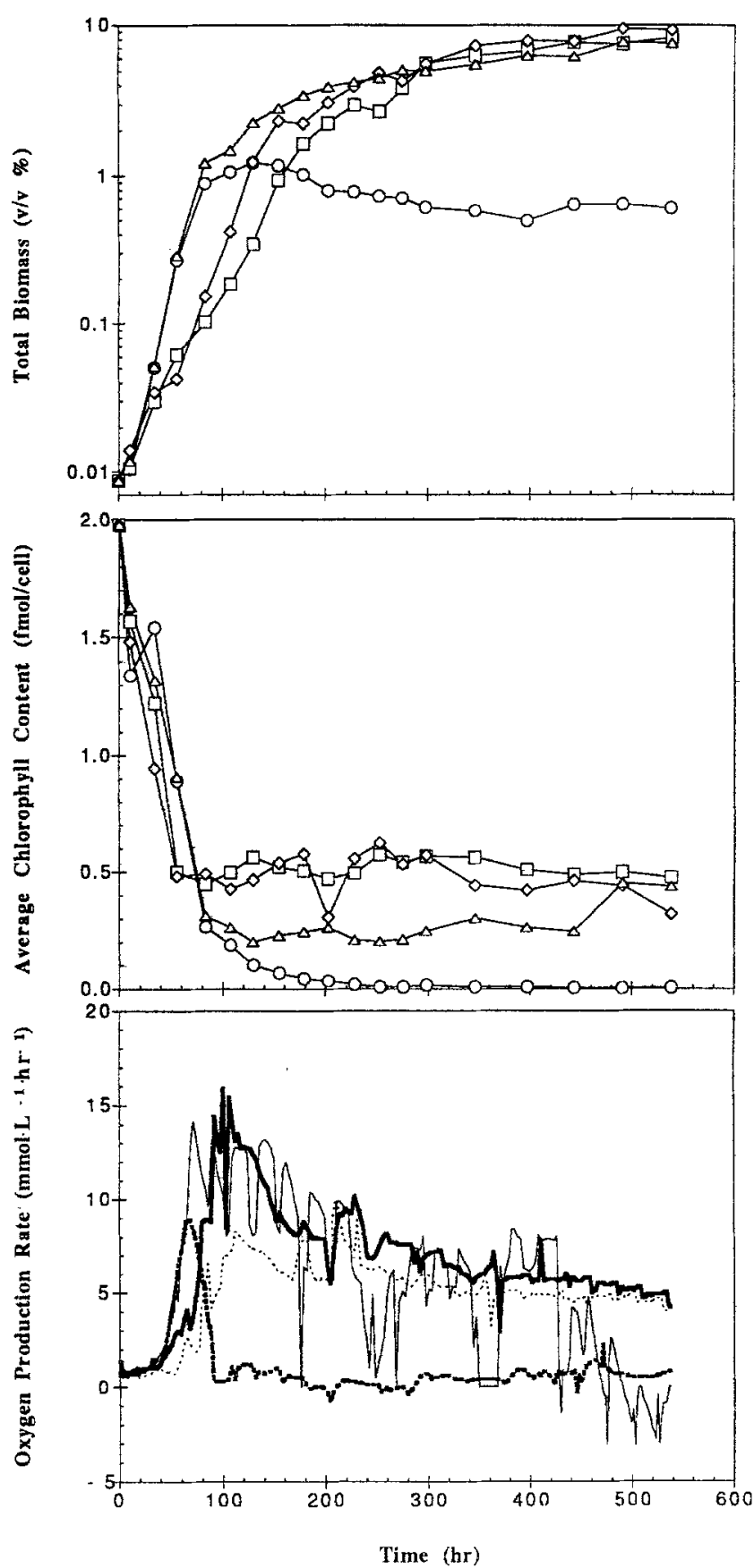

Figure 2. Comparison of growth curves in PBRs with different medium supply / removal rate. Growth curves are shown in the units of biomass due to highly variable average cell size. The four PBRs used here were: one batch mode PBR(O); one PBR with off-line medium exchange (whose medium change by centrifuge and resuspension started after the cell concentration reached $4 \cdot 10^{7}$ cells $/ \mathrm{mL}, \Delta)$; two PBRs with continuous perfusion with rates of $0.15 \mathrm{~mL} / \mathrm{min}$ ( 3 times the total reactor volume a day, $\square$ ) and $0.30 \mathrm{~mL} / \min (0)$.

Figure 3. The time profiles of chlorophyll content per cell. The symbols used are as in Figure 2: batch $(O)$, semi-batch with 1 VVD medium exchange $(\Delta)$, and continuous perfusion with 3 VVD (ㅁ) and 6 VVD $(0)$. The initial high chlorophyll content was due to the higher average cell volume (refer to text) of actively growing cells.

Figure 4. The measurement of oxygen production rate. The oxygen production in the PBR with batch mode is shown by the thick dotted line. The thin solid and thin dotted lines are from the PBRs with 1 VVD and 3 VVD medium exchange rate, respectively. The thick solid line represents the PBR with 6 VVD medium exchange.

\section{CONCLUSION}

A novel photobioreactor system was constructed and operated in a continuous perfusion mode to achieve high-density photoautotrophic algal cultures. When the PBR operated in perfusion mode with a perfusion rate of 3 to 6 reactor volumes a day, the LED-based perfusion PBR could support high-density algal cultures up to the cell concentration of $4.10^{9}$ cells $/ \mathrm{mL}$ and the total cell volume fraction of $9.4 \% \mathrm{v} / \mathrm{v}$ (about $25 \mathrm{~g}$ dry weight $/ \mathrm{L}$ ). The 
highest oxygen production rate was about 13 to $15 \mathrm{mmol} /(\mathrm{L} \cdot \mathrm{h})$. Nutritional limitations could be overcome by continuous perfusion, supplying the medium components to the culture without increasing osmolarity, while removing potentially inhibitory cellular wastes.

The data presented here shows that PBR technology may be significantly improved. Advances will most likely come through the improved understanding of the underlying biological dynamics. A proper balancing of biological and physical factors will allow highdensity algal cultures in enclosed PBRs to be economically feasible for the production of high-value algally-derived products.

ACKNOWLEDGMENTS This project was funded in part by Grant \#G-NAGW-2608 from NASA Headquarters and by Grant \#DE-FG22-93PC93212 from the Department of Energy.

\section{REFERENCES}

Avron, M. (1989). The efficiency of biosolar energy conversion by aquatic photosynthetic organisms. In: Microbial Mats: Physiological ecology of benthic microbial communities, Cohen, Y. and Rosenberg, E. eds. pp. 385-387, Washington, D.C.: American Society for Microbiology.

Benemann, J.R., Koopman, B.L., Weissman, J.C., Eisenberg, D.E. and Goebel, R.P. (1980). Development of microalgae waste water treatment and harvesting technologies in California. In: Algae Biomass: Production and Use, Shelef, G. and Soeder, C.J. eds. pp. 457-496, Amsterdam: Elsevier/North-Holland Biomedical Press.

Benemann, J.R., Tillett, D.M. and Weissman, J.C. (1987). Trends Biotechnol. 5:47-53.

Borowitzka, M.A. (1992). J. Appl. Phycol. 4: 267-279.

Bradley, P.M. (1991). J. Phycol. 27: 317-321.

Evans, L.V. (1991). J. Phycol. 27: 322-326.

Gafford, R.D. and Richardson, D.E. (1960). J. Biochem. Microbiol. Technol. Eng. 2(3): 299 311.

Geider, R.J. and Osborne, B.A. (1992). Algal Photosynthesis. New York: Chapman and Hall.

Glombitza, K. W. and Koch, M. (1989). Secondary metabolites of pharmaceutical potential. In: Algal and Cyanobacterial Biotechnology. Cresswell, R.C. and Rees, T.A.V. and Shah, H. eds. pp. 161-238, Harlow: Longman Scientific \& Technical.

Hannan, P.J. and Patouillet, C. (1963). Appl. Microbiol. 11:446-449.

Hipkins, M.F. and Baker, N.R. (1986). Photosynthesis Energy Transduction: A Practical Approach. Oxford: IRL Press.

Hoover, J.K. (1984). Chloroplasts. New York: Plenum Press.

Hoppe, H.A., Levring, T. and Tanaka, Y. (1979). Marine Algae in Pharmaceutical Science. Berlin: Walter de Gruyter.

Kreslavsky, V.D., Makarov, A.D., Brandt, A.B., Kiseleva, M.I., Mukhin E.N., Rusieva, R.Kh., Yakunin, A.F. and Rudenko, T.I. (1988). Fiziol. Rast. 35(6): 1162-1169

Lee, C.-G. and Palsson, B.O. (1994). Biotechnol. Bioeng. 44:1161-1167.

Lee, C.-G. and Palsson, B.O. (1995). J. Ferment. Bioeng. 79(3):257-263.

Mandalam, R.K. (1994). Characterization of High-Density Microalgal Cultures. Ph.D. Thesis. Ann Arbor: University of Michigan.

Pratt, R. (1944). Amer. J. Bot. 31:418-421

Pratt, R., Daniels, T.C., Eiler, J.J., Gunnison, J.B., Kumler, W.D., Oneto, J.F., Strait, L.A., Spoehr, H.A., Hardin, G.J., Milner, H.W., Smith, J.H.C. and Strain, H.H. (1944). Science. 99:351-352.

Richmond, A. (1986). Microalgae of Economic Potential. In: Handbook of Microalgal Mass Culture. Richmond, A. ed. pp. 199-243. Boca Raton: CRC Press.

Takano, H., Takeyama, H., Nakamura, N., Sode, K., Burgess, J.G., Manabe, E., Hirano, M. and Matsunaga, T. (1992). Appl. Biochem. Biotechnol. 34/35:449-458.

Vonshak, A. (1986). Laboratory Techniques for the Cultivation of Microalgae. In: Handbook of Microalgal Mass Culture. Richmond, A. ed. pp. 117-145. Boca Raton: CRC Press. 